Avrupa Bilim ve Teknoloji Dergisi

Özel Sayı, S. 428-435, Ekim 2019

(C) Telif hakkı EJOSAT'a aittir

Araștırma Makalesi
European Journal of Science and Technology

Special Issue, pp. 428-435, October 2019

Copyright C 2019 EJOSAT

$\underline{\text { Research Article }}$

\title{
Servomotorun SCADA ile Kontrolü
}

\author{
Hakan Terzioğlu ${ }^{*}$, Gökhan Yalçın ${ }^{2}$, Mustafa Kısa ${ }^{3}$ \\ ${ }^{1}$ Department of Electrical and Energy, Konya Technical University, Konya,Turkey (ORCID: 0000-0001-5928-8457) \\ ${ }^{2}$ Department of Mechanical, Konya Technical University, Konya,Turkey (ORCID: 0000-0003-4491-0228) \\ ${ }^{3}$ Department of Visual, Auditory, Techniques and Media productions , Konya Technical University, Konya,Turkey (ORCID: 0000-0002-0035-5077) \\ *(hterzioglu@ktun.edu.tr)
}

\begin{abstract}
(Bu yayın International Congress on Human-Computer Interaction,Optimization and Robotic Application kongresinde sözlü olarak sunulmuştur.)
\end{abstract}

(First received 1 August 2019 and in final form 25 October 2019)

(DOI: $10.31590 /$ ejosat.638394)

ATIF/REFERENCE: Terzioğlu, H., Yalçın, G. \& Kısa, M. (2019). Servomotorun SCADA ile Kontrolü. European Journal of Science and Technology, (Special Issue), 428-435.

\section{Özet}

Servomotorlar, step (adım) motorlar, asenkron motorlar endüstride yaygın olarak tercih edilen elektrik motorlarındandır. Bu motorlar içerisinde servo ve step motorlar konum kontrolleri gerektiren uygulamalarda daha fazla kullanılır. Döndürme momentlerinin yüksek olması, döndürme momentinin iki katına kadar olan değerlere kısa süreli olarak yüklenebilmesi, atalet (kalkış) momentleri küçük olması, 1-10000 devir / dakika arasındaki devir sayılarından ayarlanabilmeleri gibi avantajlarından dolayı servomotorlar hassas konum kontrolü gerektiren yerlerde tercih edilmektedir. Bu çalışmada Delta marka servomotorun kontrolü SCADA kullanılarak gerçekleştirilmiştir. Servomotorun kontrolünde Delta marka PLC, servomotor hız kontrolü cihazı ve HMI panel tercih edilmiştir. Gerçekleştirilen SCADA yazılımında servomotorun çalışma parametreleri HMI ekranından belirlenmektedir. Ekran üzerinden servomotorun çalışma açısı, kaç devirde çalışacağı, kaç defa aynı işlemi gerçekleştireceği parametre olarak belirlenebilmektedir. Böylece servomotorun farklı kullanım yerlerinde istenilen şekilde çalışması sağlanmış olacaktır.

Anahtar Kelimeler: Servomotor, PLC, HMI, SCADA

\section{Control of Servomotor with SCADA}

\begin{abstract}
Servomotors, stepper motors, induction motors are among the most preferred electric motors in the industry. In these motors, servo and stepper motors are used more in applications requiring position controls. Servomotors are preferred in places requiring precise position control due to their advantages such as high rotational moments, short-time loading of values up to twice the rotational torque, small moment of inertia, adjustable speed between 1-10000 rpm. In this study, the control of Delta servomotor was realized by using SCADA. In the control of the servomotor, Delta brand PLC, servomotor speed control device and HMI panel are preferred. In the SCADA software, the operating parameters of the servomotor are determined from the HMI screen. The operating angle of the servomotor, the number of revolutions and the number of times that the servo motor will perform the same operation can be defined as parameters. Thus, the servomotor will be provided to operate in different places as desired.
\end{abstract}

Keywords: Servomotor, PLC, HMI, SCADA.

\section{Giriş}

Servo, herhangi bir mekanizmanın işleyişini hatayı algılayarak yan bir geri besleme düzeneğinin yardımıyla denetleyen ve hatayı gideren otomatik aygıttır. Robot teknolojisinde en çok kullanılan motor çeşididir. Bu sistemler mekanik olabileceği gibi elektronik, hidrolik-pnömatik veya başka alanlarda da kullanılabilmektedir. Servo motorlar; çıkış, mekaniksel konum, hız veya ivme gibi 
parametrelerin kontrol edildiği, özetle hareket kontrolü yapılan bir düzenektir.ve servo motor lar batlerli motordurlar Servo motor içerisinde herhangi bir motor AC, DC veya step motor bulunmaktadır.

Servomotorlar, step (adım) motorlar, asenkron motorlar endüstride yaygın olarak tercih edilen elektrik motorlarındandır. Bu motorlar içerisinde servo ve step motorlar konum kontrolleri gerektiren uygulamalarda daha fazla kullanılır. Döndürme momentlerinin yüksek olması, döndürme momentinin iki katına kadar olan değerlere kısa süreli olarak yüklenebilmesi, atalet (kalkış) momentleri küçük olması, 1-10000 devir / dakika arasındaki devir sayılarından ayarlanabilmeleri gibi avantajlarından dolayı servomotorlar hassas konum kontrolü gerektiren yerlerde tercih edilmektedir. Servo motorun hız kontrolü üzerine birçok çalışma yapılmaktadır. Kalıcı mıknatıslı senkron motor (PMSM) servo sistemi için gerçekleştirilen çalışmada hız kontrol performansını optimize etmek için, öngörüsel fonksiyonel kontrol (PFC) metodu uygulanmıştır. Bu yöntem etkinliğini doğrulamak için bu PFC yöntemleri ve orantısız integral yöntemle simülasyon ve deney karşılaştırmaları yapılmıştır ( $\mathrm{Liu} \& \mathrm{Li}, 2011$ ). Ayrıca kayma mod kontrol kullanılarak gerçekleştirilen çalışmalar la birlikte (F-J Lin \& Chiu, 1998; Shyu \& Shieh, 1996) Fuzzy yöntemi kullanılarak servomotor kontrolünün gerçekleştirildiği çalışmalar da yapılmıștır (Izuno, Takeda, \& Nakaoka, 1992; Faa-Jeng Lin, Wai, \& Chen, 1998; Wai \& Lin, 1999). Ayrıca yüksek örnekleme frekans kontrolü (akım döngüsü: $16 \mathrm{kHz}$, darbe genişliği modülasyon devresi: 4-8 MHz) gerekliliği sayesinde basit vektör hesaplamada donanımdaki mevcut vektör kontrol cihazı kullanılarak servomotor hız kontrolü gerçekleştirilmiştir. (Kung \& Tsai, 2007)

Servomotorların uzaktan kontrolünün gerçekleştirildiği çalışmalar gerçekleştirilmiştir. Bu çalışmalarda kablosuz çift yönlü servo motor sürücüsü, elektrik çarpması gerektirmeyen ve tamamen sızdırmazlığın kesin avantajlarını alan bir çalışma gerçekleştirilmiştir. $\mathrm{Bu}$ çalı̧̧mada fizibilite ve kontrol edilebilirliği doğrulamak için hem hesaplama hem de deneysel sonuçlar sunularak prototip için iletim mesafesi 130 mm'ye ulaşabilmiş ve iletim verimliliği \% 85'e kadar çıkılmıştır.(Jiang et al., 2019)

Bu çalı̧̧mada Delta marka servomotorun kontrolü SCADA kullanılarak gerçekleştirilmiştir. Servomotorun kontrolünde Delta marka PLC, servomotor hız kontrolü cihazı ve HMI panel tercih edilmiştir. Gerçekleştirilen SCADA yazılımında servomotorun çalışma parametreleri HMI ekranından belirlenmektedir. Ekran üzerinden servomotorun çalışma açısı, kaç devirde çalışacağı, kaç defa aynı işlemi gerçekleştireceği parametre olarak belirlenebilmektedir. Böylece servomotorun farklı kullanım yerlerinde istenilen şekilde çalışması sağlanmış olacaktır.

\section{Materyal ve Metod}

\subsection{Servomotor}

Motor güç mili dışında, rotorun konumunu ya da hızını belirlemek maksadıyla bir çıkış mili daha olan ve bu mile bağlı enkoder, potansiyometre vb. elemanlar ile geri besleme alınabilecek bir çıkışı olan motorlara servomotor denir. Servomotorların bazı tipleri firçalı bazıları ise firçasız imal edilmektedir. Bunlardan DA (Doğru Akım) servomotorlar firçalı, AA (Alternatif Akım) servomotorlar ise firçasızdır. Dijital kontrollü, hassas işleme ya da çalışma istenilen makinelerde çok tercih edilen servomotorların bazı özellikleri şu şekilde sıralanabilir (Anonim ,2011).

- Döndürme momentleri yüksektir.

- Döndürme momentinin iki katına kadar olan değerlere kısa süreli olarak yüklenebilirler.

- Atalet (kalkış) momentleri küçüktür ve verilen komutları gecikme olmadan algılar ve yerine getirirler.

- Çok sık aralıklı olarak hareket edebilirler. Yani dur-kalk yapma sayılarının çok olması motoru olumsuz etkilemez.

- 1-10000 devir / dakika arasındaki devir sayılarından herhangi birisine kolayca ayarlanabilir.

\subsubsection{AA servomotor}

AA servomotorlar, genellikle iki fazlı sincap kafesli indüksiyon tipi motorlardır. İki fazlı asenkron motorlar, büyük güçlü yapılmakla birlikte genellikle otomatik kontrol sistemlerinde kullanılmak amacı ile küçük güçte yapılır. Fırça ve kolektör bulunmadığından arıza yapma ihtimalleri az, bakımları ise kolaydır (Anonim ,2011).

\section{AA servomotor karakteristikleri}

Servomotorlar kullanımları gereği çok sık şekilde ivmelenme ve yavaşlatma işlemlerine maruz kaldıklarından, maksimum moment değerleri anma moment değerlerinden daha fazla olmalıdır. DA motorlarda anma momentlerinin aşılması durumunda komütatör aksamında kıvılcımlaşma olayı gözükür. Aynı şekilde hız arttıkça moment değeri de çok hızlı bir şekilde düşer. AA servomotorlarda ise yukarıda bahsedilen kıvılcımlanma olayı, yapısı dolayısıyla görülmez. Fırçasız servomotorlar maksimum momenti düşürmeden yüksek hız limitlerinde çalıştırılabilirler.

Servomotorların genel çalışma sistemine ait blok diyagram ise Şekil 1'de gösterilmiştir (Coşkun \& Mehmet, 2004). 


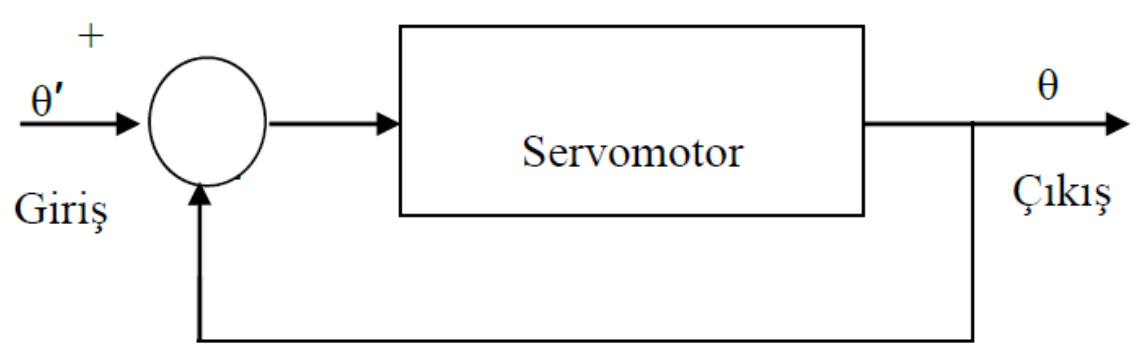

Şekil 1. Servomotor çalışma sisteminin blok diyagramı

Pozisyon kontrolü aşamasında pozisyon açısı $\theta$, istenilen pozisyon $\theta^{\prime}$ olarak ele alınırsa sürücü devrenin bu aşamada üreteceği sinyalin büyüklüğü açı olarak

$$
\Delta \theta=\theta^{\prime}-\theta
$$

olur.

Servomotorun sembolik gösterimi ise Şekil 2'de gösterilmiştir.

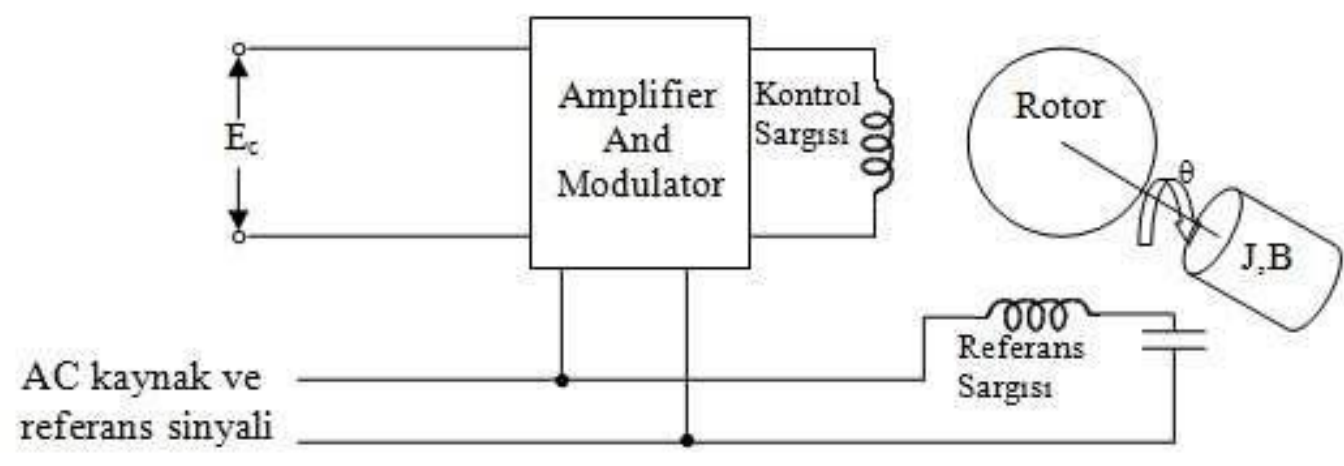

Şekil 2. AA Servomotorun sembolik gösterimi

\subsection{SCADA ile Servomotor Kontrolü}

Bu çalışmada AC Servomotorun SCADA ile kontrolü gerçekleştirilmiştir.

\subsubsection{PLC, Operatör Paneli, Servomotor ve Sürücü}

Bu çalışmada Delta Marka 750 W 17 bit 3000 devir/dk Frensiz 2,39 Nm'lik torka sahip ECMA-C20807GS kodlu AC Servo Motor kullanılmıştır. Sürücü olarak da ASD-B2-0721-B kodlu Delta marka $750 \mathrm{~W}$ sürücü tercih edilmiştir.

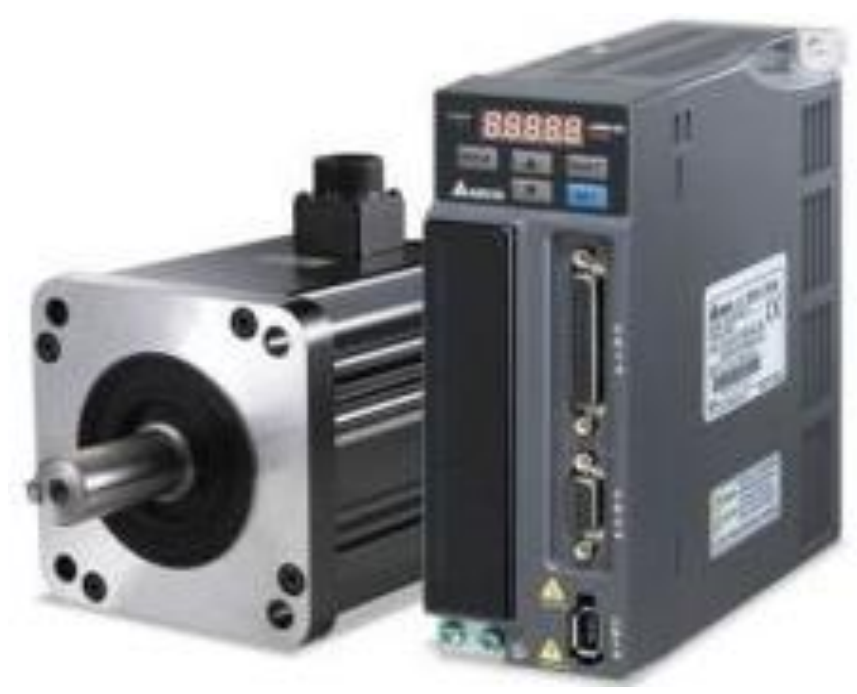




\section{European Journal of Science and Technology}

Şekil 3. Servomotor ve Sürücü

PLC olarak Delta marka DVP-12SA kodlu 8 girişli 4 transistör çıkışlı PLC ile DOP-B serisi operatör paneli tercih edilmiştir.

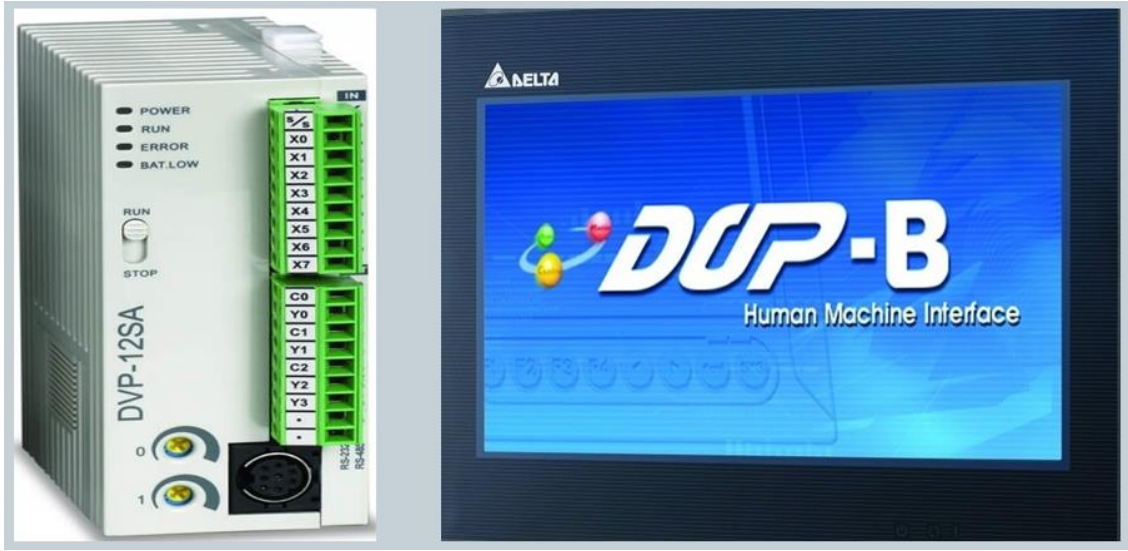

Şekil 4. Delta PLC ve Operatör Paneli

\subsubsection{SCADA Sistem Tasarımı}

Bu çalışmada AC Servomotorun SCADA ile kontrolü gerçekleştirilmiştir.Şekil 5'de SCADA sistemine ait pano tasarımının genel yapısı görülmektedir.

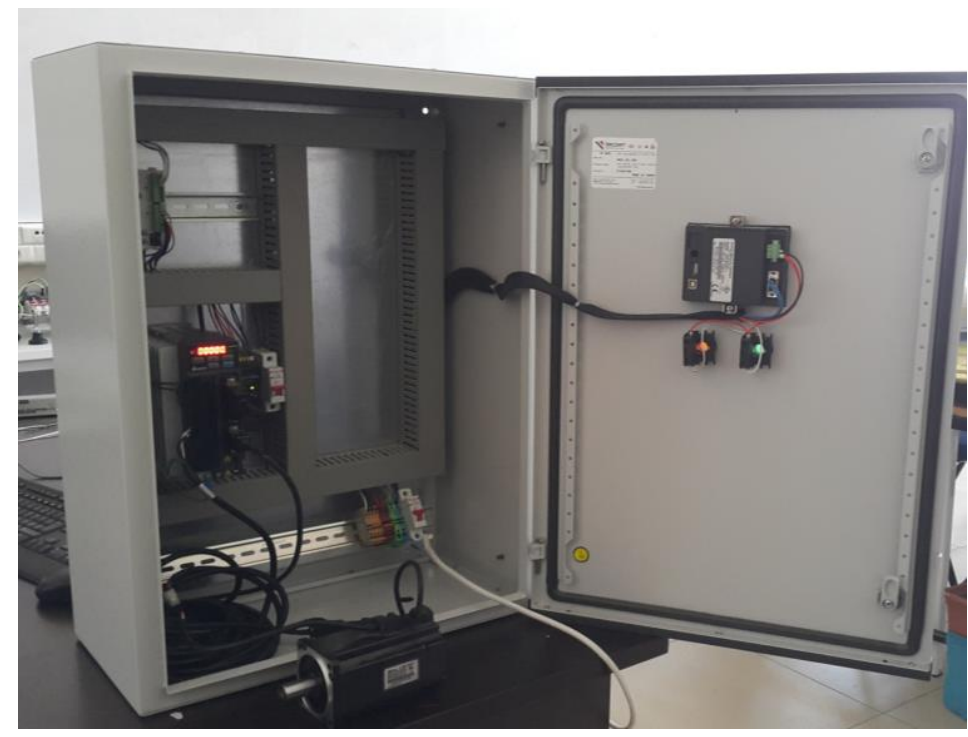

Şekil 5. Panonun genel görünümü

Şekil 6'de panonun iç görünüşü görülmektedir. Burada kontrolör olarak PLC kullanılmıştır. PLC, HMI dan gelen bilgilere bağlı olarak Servo motor sürücüsüne aktarmakta ve böylece belirlenen şartlarda Servo motor çalıştırılmaktadır. 


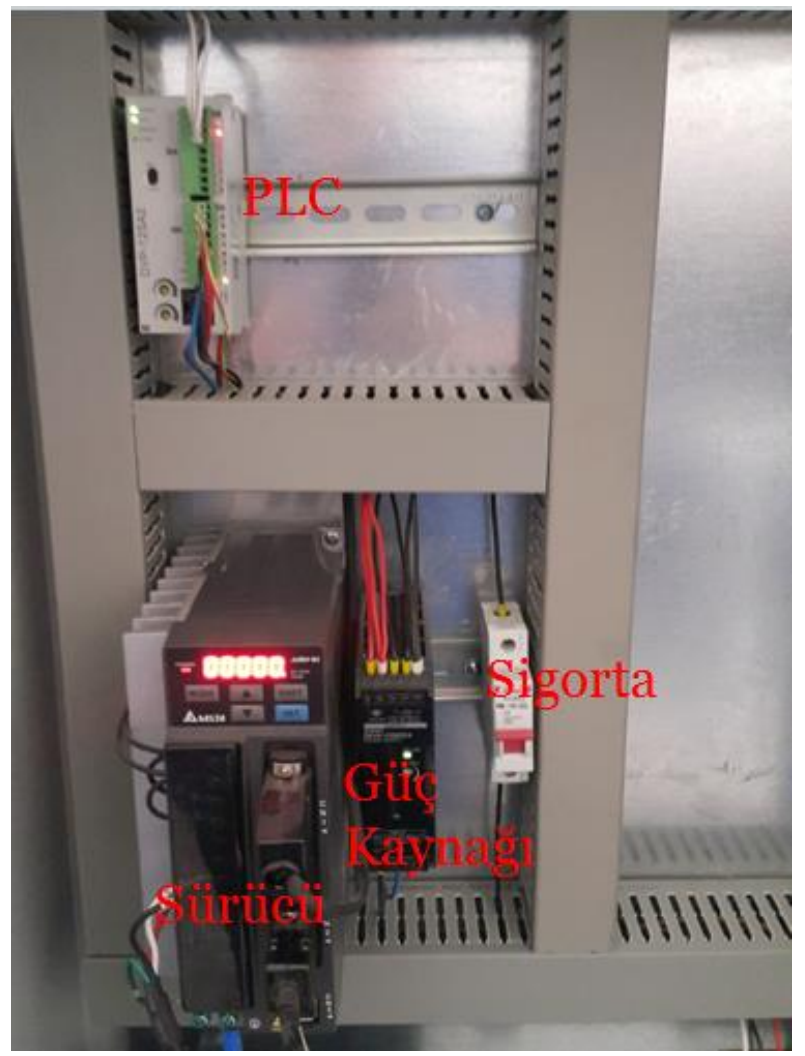

Şekil 6. Pano iç görünüşü

Şekil 4'de görünen malzemelerin çalışma anındaki görüntüleri Şekil 7'de verilmiştir.

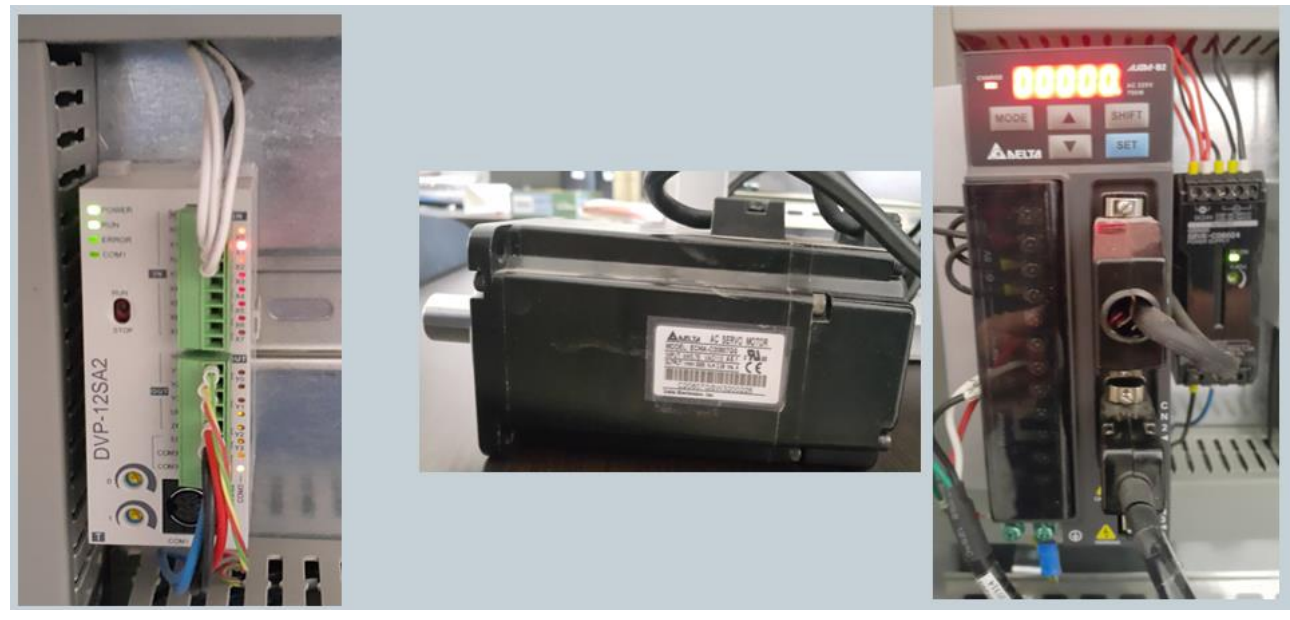

Şekil 7. PLC, Servo Motor ve Sürücü

Şekil 8'de panonun kapak görünüşü ile HMI panel bağlantısı görülmektedir. Şekil 8'de tasarlanan operatör paneli sayfası ve sistem start stop butonları görülmektedir. HMI panelden parametreler belirlendikten sonra HMI panel üzerindeki SERVO ON/OFF butonu SERVO ON konumunda olduğunda ve Start butonuna basıldığında Servo Motor belirlenen koşullarda ve sayıda çalı̧̧maktadır. 


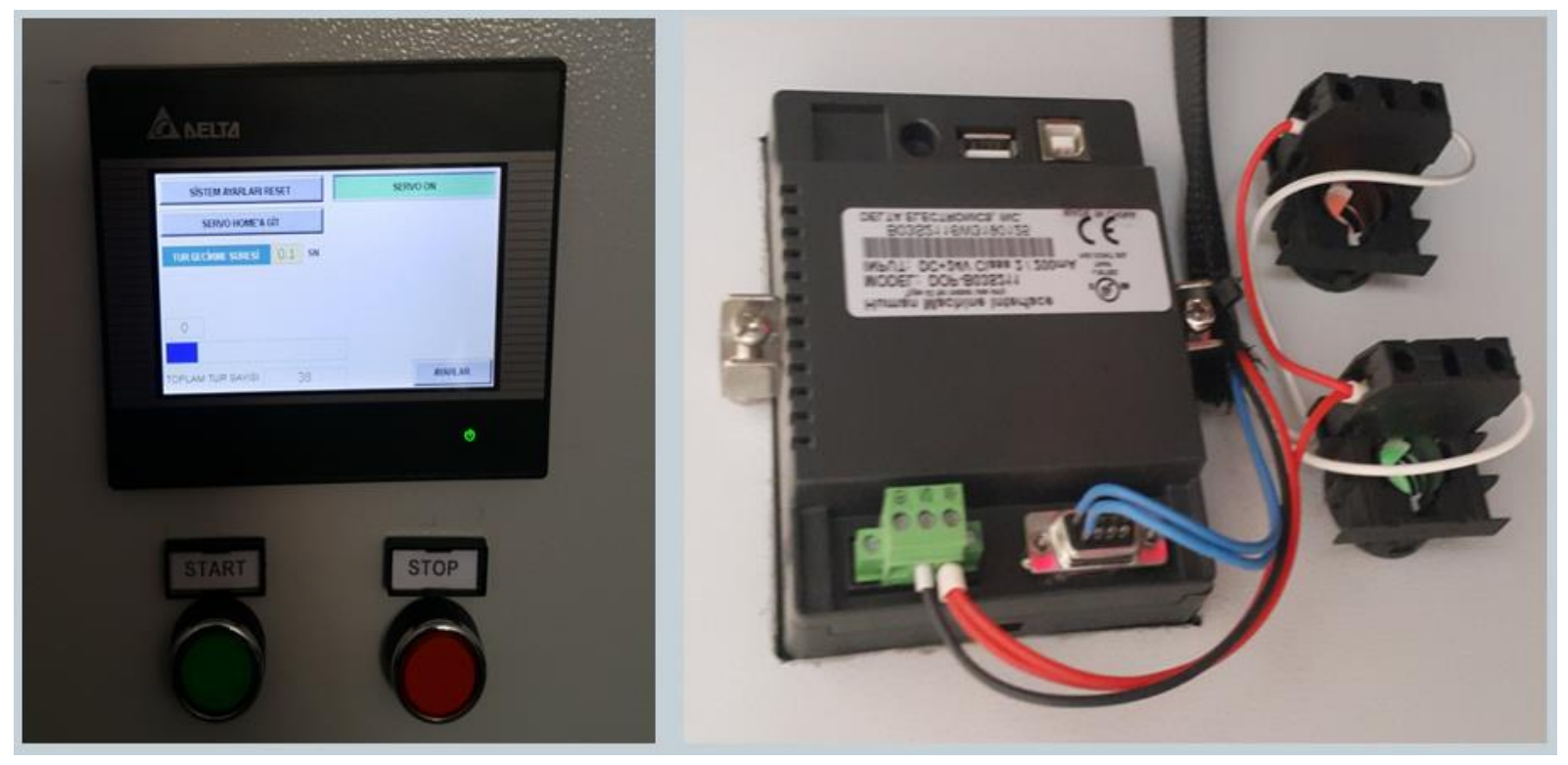

Şekil 8. Pano kapak görünüşü

Şekil 9 ve Şekil 10'da tasarlanan operatör paneli sayfasında

- SERVO OFF: ON/OFF butonu Servo Motorun sürücü ile bağlantı kurmasını sağlamaktadır.

- Sistem Ayarları Reset: Ayarlar sayfasındaki değişkenleri yazılımdaki ilk değerleri atamak için kullanılır.

- SERVO Home'a Git: Servo Motorun konumu açısal olarak sıfır noktası olarak kabul edilen noktaya getirmek için kullanılır.

- Ayarlar: Servo Motorun çalışma ayarlarının belirlendiği sayfadır.

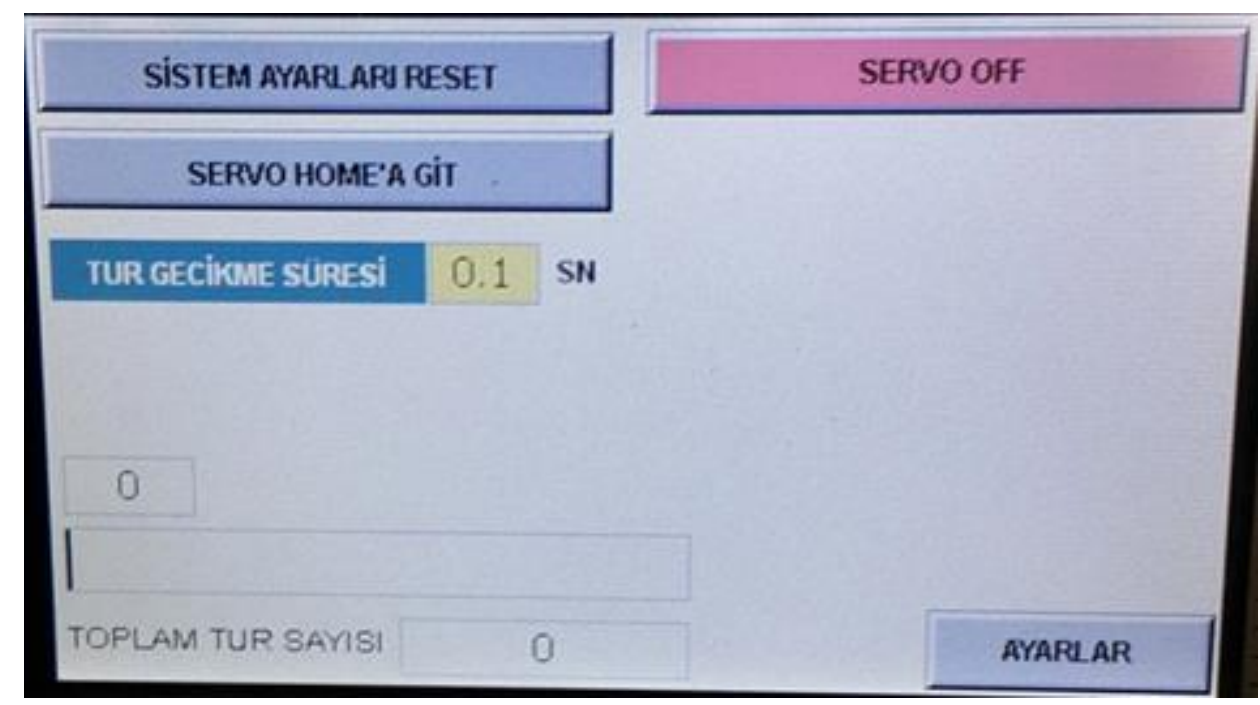

Şekil 9: HMI yazılımı 


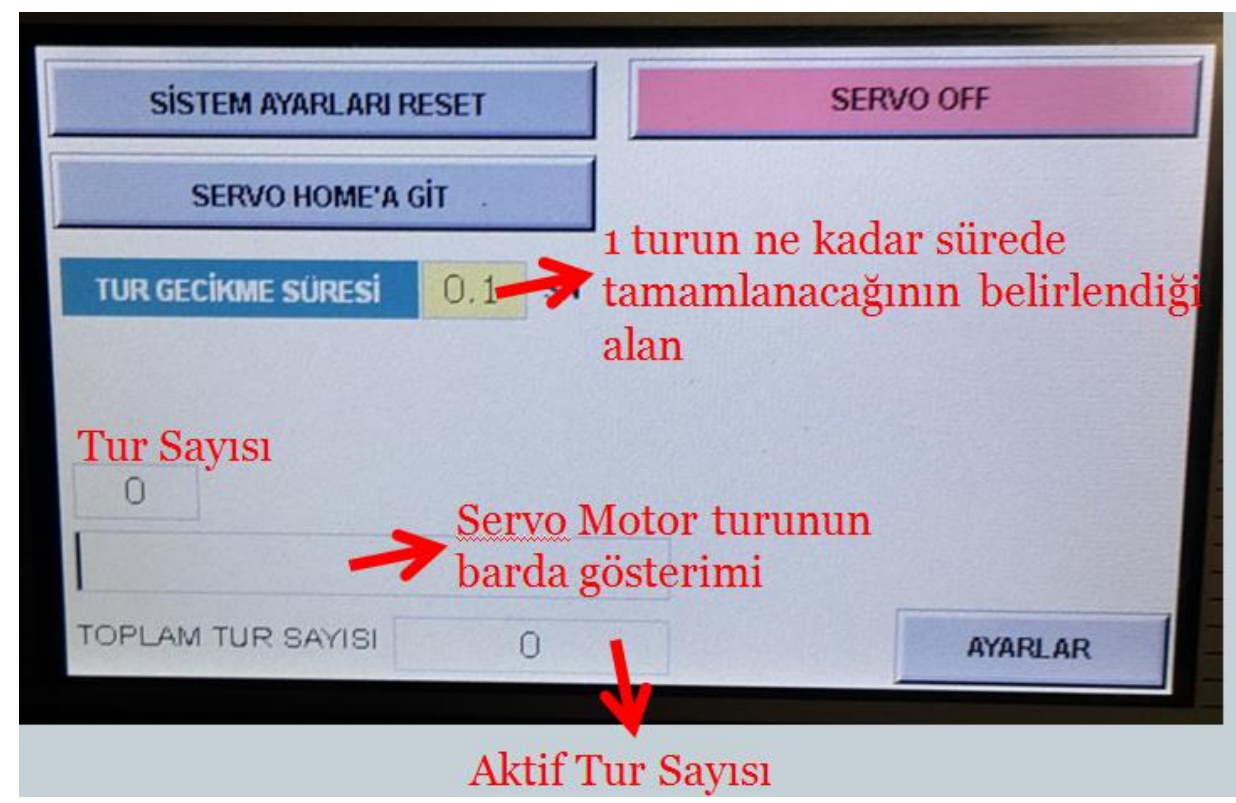

Şekil 10: HMI yazılımı

Şekil 11'de tasarlanan ayarlar sayfasından Servo motorun;

- Kaç derece çalışacağ 1 ,

- Hızının ne olacağı,

- Kaç defa aynı hareketi yapacă̆ı,

bu sayfadan ayarlanmaktadır.

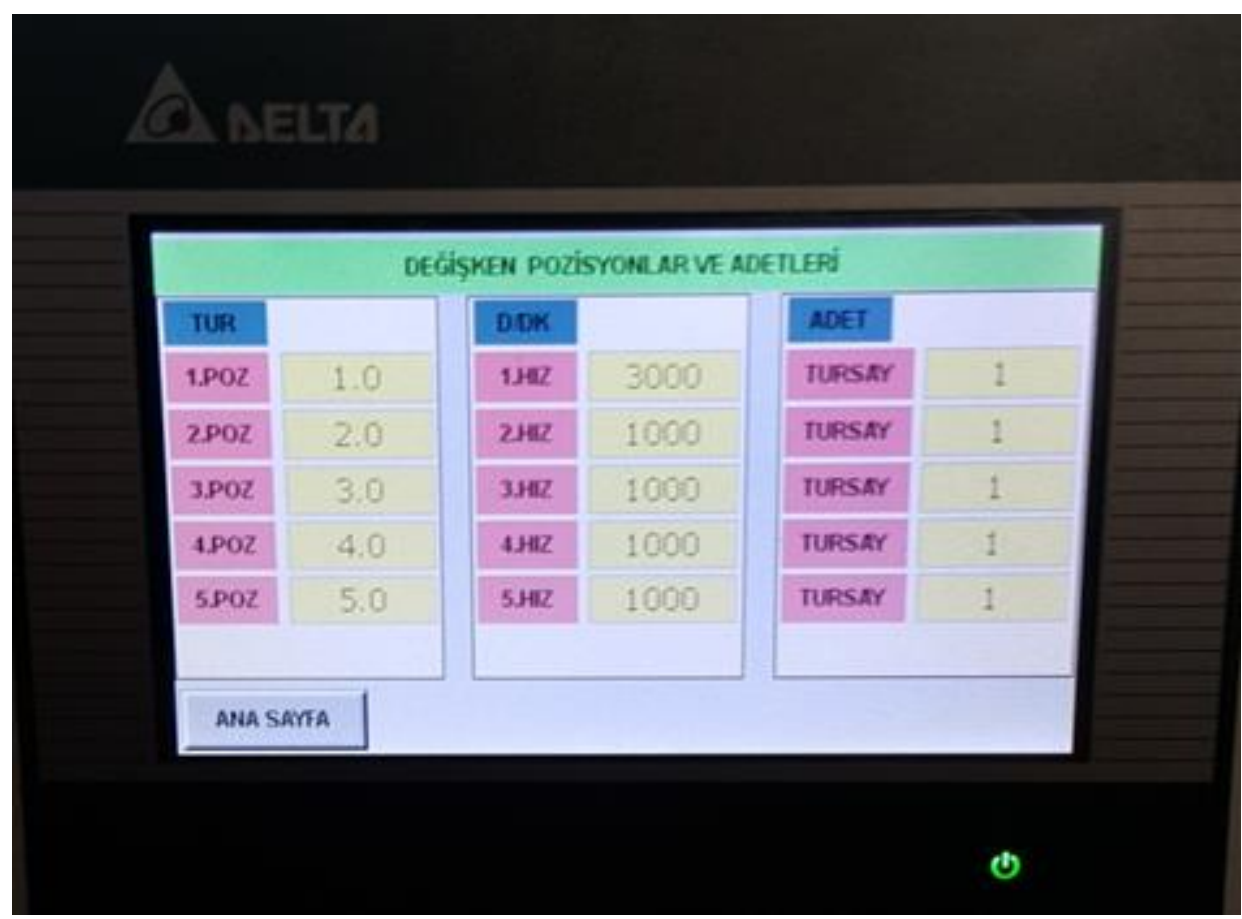

Şekil 11. Ayarlar Sayfası 


\section{Araştırma Sonuçları ve Tartışma}

\subsection{Sistem Çalışması}

Şekil 12’de SCADA sistemi çalıştırıldığındaki ekran görüntüsü görülmektedir.

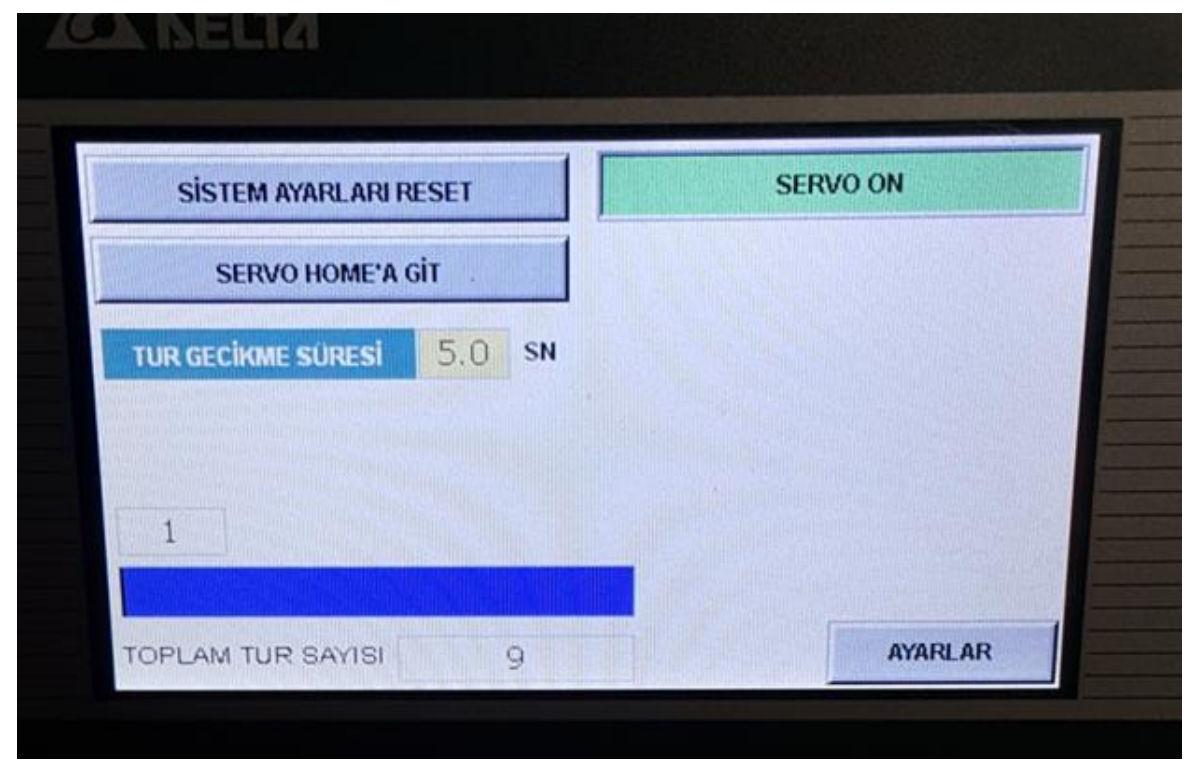

Şekil 10. Çalışma Ekranı

\section{Sonuç}

Gerçekleştirilen bu çalışmada AC servo motorun kontrolü SCADA ile gerçekleştirilmiştir. Gerçekleştirilen SCADA sistemi ile AC Servo motor kullanılarak istenilen derecede, istenilen hızda ve istenilen sayıda hareketin gerçekleştirilmesi sağlanmıştır. Bu sistem amacına uygun olacak ve gücü yeterli olabilecek her sistemde kullanılabilir.

\section{Acknowledge}

Bu çalışma Konya Teknik Üniversitesi ve Selçuk Üniversitesi Bilimsel Araştırma Koordinatörlüğü 18401098 numaralı proje ile desteklenmiştir.

\section{Kaynaklar}

Anonim, 2011, Step ve servomotorlar, http://megep.meb.gov.tr/mte_program_modul/moduller_pdf/Stepservo\%20Motorlar.pdf(10.01.2013).

Coşkun, İ., \& Mehmet, I. (2004). Position and Speed Control of Servomotor Using Microcontroller. Gazi University Journal of Science, 17(3), 115-125.

Izuno, Y., Takeda, R., \& Nakaoka, M. (1992). New fuzzy reasoning-based high-performance speed/position servo control schemes incorporating ultrasonic motor. IEEE Transactions on Industry applications, 28(3), 613-618.

Jiang, C., Chau, K., Lee, C. H., Han, W., Liu, W., \& Lam, W. (2019). A Wireless Servo Motor Drive with Bidirectional Motion Capability. IEEE Transactions on Power Electronics.

Kung, Y.-S., \& Tsai, M.-H. (2007). FPGA-based speed control IC for PMSM drive with adaptive fuzzy control. IEEE Transactions on Power Electronics, 22(6), 2476-2486.

Lin, F.-J., \& Chiu, S.-L. (1998). Adaptive fuzzy sliding-mode control for PM synchronous servo motor drives. IEE ProceedingsControl Theory and Applications, 145(1), 63-72.

Lin, F.-J., Wai, R.-J., \& Chen, H.-P. (1998). A PM synchronous servo motor drive with an on-line trained fuzzy neural network controller. IEEE Transactions on Energy Conversion, 13(4), 319-325.

Liu, H., \& Li, S. (2011). Speed control for PMSM servo system using predictive functional control and extended state observer. IEEE Transactions on Industrial Electronics, 59(2), 1171-1183.

Shyu, K.-K., \& Shieh, H.-J. (1996). A new switching surface sliding-mode speed control for induction motor drive systems. IEEE Transactions on Power Electronics, 11(4), 660-667.

Wai, R.-J., \& Lin, F.-J. (1999). Fuzzy neural network sliding-mode position controller for induction servo motor drive. IEE Proceedings-Electric Power Applications, 146(3), 297-308. 